\title{
Reflexões sobre documentos sensíveis, informação e memória no contexto do regime de exceção no Brasil (1964- 1985)
}

\author{
Icléia Thiesen ${ }^{I}$ \\ https://orcid.org/0000-0002-3137-8933 \\ ${ }^{I}$ Universidade Federal do Estado do Rio de Janeiro, Rio de Janeiro, RJ, Brasil. \\ Pós-doutorado em Ciência da Informação pela Université Paul Sabatier, Toulouse 3 \\ (2007-2008). Doutorado e Mestrado em Ciência da Informação pelo IBICT/CNPq, \\ em convênio com a UFRJ/ECO (1997 e 1992, respectivamente). \\ Professora Titular da UNIRIO, Departamento de História/PPGH/PPGB. \\ Coordenadora do LAHODOC - Laboratório de História Oral, informação e Documentação.
}

http://dx.doi.org/10.1590/1981-5344/3890

Entre informar, reter e conhecer há meandros inúmeras vezes desconhecidos dos pesquisadores que manuseiam e analisam documentos primários custodiados pelas instituições arquivísticas. As atividades que originaram a produção documental merecem ser esquadrinhadas, para que evidenciem as condições históricas que tornaram possível sua fabricação, revelando a natureza dos arquivos que abrigam os chamados documentos sensíveis que, por suas características singulares, constituem desafios com os quais se deparam os que deles fazem uso. Este artigo se dedica a refletir sobre tais documentos, em suas relações com a informação de que são portadores e a memória que se deseja reconstruir. Problematiza, ainda, o testemunho enquanto recurso metodológico e sua validação científica na busca da verdade dos fatos e acontecimentos que geraram os documentos produzidos pelo regime de exceção que vigeu de 1964 a 1985 no Brasil, reflexos de experiências vivenciadas por aqueles que se opuseram ao regime. Ao analisar o testemunho de Inês Etienne Romeu, única sobrevivente da Casa da Morte em Petrópolis (RJ), abre a discussão sobre o jogo político travado na luta pelo esclarecimento do passado recente do país. 
Palavras-chave: Documentos sensíveis. Testemunhos. Informação e memória. Ditadura de 1964. Justiça de transição.

\title{
Reflections on sensitive documents, information and memory in the context of the exception regime in Brazil (1964-1985)
}

\begin{abstract}
Between inform, retain and understand there are innumerable meanders unknown to researchers who manipulate and analyze primary documents guarded by archival institutions. The activities that originated the documentary production deserve to be scrutinized, so that they show the historical conditions that made possible its manufacture, revealing the nature of the archives that house the so-called sensitive documents that, due to their singular characteristics, constitute challenges for those who make use of them. This article is dedicated to the reflection on such documents, regarding their relations with the information they bear and the memory that one wishes to reconstruct. It also problematizes the testimony as a methodological resource and its scientific validation in the search for the truth of facts and events that generated the documents produced by the Brazilian Dictatorship regime, between 1964 and 1985, reflecting the experiences of those who opposed the regime. The analyses of Inês Etienne Romeu testimony, the only survivor of the House of Death in Petrópolis (RJ), opens the discussion about the political game caught in the struggle for the elucidation of the country's recent past.
\end{abstract}

Keywords: Sensitive documents. Testimony. Information and memory. Brazilian Dictatorship.

[...] nous voulons faire comprendre ce message à tous les tyrans du monde entier que la pensée de commettre un génocide ou d'autres infractions aux droits de l'homme ne vous effleure même pas l'esprit. Tôt ou tard, I'heure des comptes sonnera et vous ne pourrez pas y échapper, parce qu'il n'y aura pas un endroit au monde où vous cacher. (LECLERC, 1999, p. 517) 
Mme Orentlicher, directrice du projet de recherches sur les crimes de guerre.

Recebido em 12.03.2019 Aceito em 12.03.2019

\section{Introdução}

O tema desta palestra se situa na fronteira de minha pesquisa recém finalizada sobre documentos sensíveis, intitulada "Entre informar, reter e conhecer: um estudo teórico-metodológico sobre documentos sensíveis em instituições arquivísticas" com os outros desafios a serem enfrentados em novo estudo sobre aspectos quali-quantitativos desses mesmos documentos. Trata-se de um estudo sobre processos de produção de documentos relativos às atividades dos governos militares (1964-1985) pertencentes ao Sistema Nacional de Informação e ContraInformações (SISNI), com o propósito de problematizar seus dispositivos de organização, mediação, recuperação e uso desde a sua concepção ${ }^{1}$.

A necessidade de assegurar a preservação e a acessibilidade duradoura dos arquivos de países em transição democrática suscitou a declaração segundo a qual "os arquivos estão no coração da sociedade de informação", por ocasião da 36a Conferência Internacional da Mesa Redonda dos Arquivos (Citra), ocorrida em Marselha, em 2002 ${ }^{2}$. Entre outras recomendações dos diretores de Arquivos nacionais e presidentes de associações profissionais nacionais, membros do Conselho Internacional de Arquivos (CIA), a declaração final considerou...

[...] a demanda urgente das vítimas de antigos regimes repressivos e as necessidades dos pesquisadores, [...] os esforços dos países latino-americanos em vista da edificação de uma sociedade justa e reconciliada na região, $[\ldots]$ o aumento considerável de documentos reunidos pelas organizações de defesa dos direitos humanos em nível mundial e o interesse histórico, social e educativo que representam para a comunidade internacional (ORGANIZAÇÃO DAS NAÇÕES UNIDAS PARA A EDUCAÇÃO, A CIENCIA E A CULTURA UNESCO, 2002, p. 4).

A amplitude das questões mostra a importância dos problemas doravante assumidos por países que seguiriam o plano de ação definido nesse evento. Como dar conta de uma série de dificuldades que estão na origem da formação desses arquivos? Onde estão? Estão acessíveis ao público? Uma vez localizados, teria havido seleção e destruição de documentos? Estão ainda protegidos por leis de acesso à informação?

${ }^{1}$ O presente artigo é fruto da Aula Inaugural proferida pela autora no Programa de Pós-Graduação em Ciência da Informação da Escola de Ciência da Informação da UFMG, realizada em 8 de março de 2017. Constitui, ainda, síntese de ideias apresentadas e debatidas em eventos acadêmicos, ao longo dos últimos anos, presentes nas referências. Agradeço o apoio do CNPq. Aqui trago uma síntese de ideias que venho apresentando em diversos eventos acadêmicos, ao longo dos dois últimos anos, presentes nas referências (THIESEN, 2016).

Disponível em: <http://portal.unesco.org/ci/fr/ev.php-URL ID=6407\&URL_DO=DO_TOPIC\&URL_SECTION=201.html > . Acesso em: 14 jan. 2016. 
Pode-se, assim, imaginar quanto esforço está ainda em curso para realizar as tarefas previstas na legislação dos arquivos nacionais dos países que se engajaram em um processo de democratização. Um trabalho de crítica deve sempre preceder o uso dos documentos de arquivo, ou seja, as fontes de pesquisa.

Entretanto, quando se trata de arquivos sensíveis, um cuidado suplementar se impõe, pois podem nos conduzir a armadilhas. O que nos parecia um tesouro pode constituir verdadeira miragem! (FRANÇOIS, 1998). O conhecimento desta fábrica de memória (ANHEIM; PONCET, 2004) pressupõe também o conhecimento das condições de produção dos documentos e, ainda, dos traços das cadeias da hierarquia e do comando das instituições produtoras dos documentos. A importância dos arquivos sensíveis pode ser medida por sua qualificação de Patrimônio da Humanidade atribuída pela UNESCO, em 2011 (ISHAQ, 2012)

Aspectos éticos, metodológicos e epistemológicos devem ser examinados, colocando em evidência as engrenagens dessa fábrica muitas vezes mortífera. Longe de guardar a verdade que surgiria de pronto aos usuários no pós-regime de exceção, será necessário desnaturalizar esses arquivos e reconstruir a memória que eles contêm. Isto significa que os arquivos e a memória enquanto construções sociais não são naturais, o que nos obriga a esclarecer a lógica que conduziu às práticas de produção, conservação, arquivamento e uso. Ter arquivos, portanto, não significa deter a memória dos acontecimentos! Condição necessária, mas não suficiente.

Para melhor compreender os processos de institucionalização da produção documentária e seu recolhimento aos arquivos, é preciso situar esta pesquisa no universo da Justiça de Transição e definir questões situadas na fronteira de campos interdisciplinares, como a Ciência da Informação, a Comunicação, História do Tempo Presente, Arquivologia e Memória Social.

Os arquivos da Ditadura se situam nos campos interdisciplinares, mas também no universo da política, das mídias, dos movimentos sociais. A análise da memória dos acontecimentos não pode ignorar a cultura política que pode "fornecer chaves de interpretação sobre um certo número de problemas-chave..." (BERSTEIN, 1999, p. 67), sempre no plural, para tentar compreender o papel dos grupos e instituições na produção e reprodução das representações sociais. Os historiadores entendem por cultura política

[...] um grupo de representações, portadoras de normas e valores, que constituem a identidade das grandes famílias políticas e que vão muito além da noção reducionista de partido político. Pode-se concebê-la como uma visão global do mundo e de sua evolução, do lugar que aí ocupa o homem e, também, da própria natureza dos problemas relativos ao poder, visão que é partilhada por um grupo importante da sociedade num dado país e num dado momento de sua história. (BERSTEIN, $1999^{3}$ apud BERSTEIN, 2009, p. 31)

\footnotetext{
${ }^{3}$ BERSTEIN, S. (Dir.). Les cultures politiques en France. Paris: Seuil, 1999.
} 
Na continuidade de sua argumentação, o autor explica que essa noção teve seu apogeu na década de 1960, tendo sido objeto de diferentes escolas e de muitos questionamentos. Assim,

Por meio de estudos empíricos, [os historiadores] constatam a existência, num dado momento da história, de vários sistemas de representações coerentes, rivais entre si, que determinam a visão que os homens que deles participam têm da sociedade, de sua organização, do lugar que aí ocupam, dos problemas de transmissão do poder, sistemas que motivam e explicam seus comportamentos políticos. (BERSTEIN, 2009, p. 32)

Para além das questões já colocadas, ressalta-se "a força explosiva da memória". Pierre Nora, em texto publicado na revista Musas, de 2009, constata o que é novo na atualidade:

A reivindicação de uma verdade que é mais verdadeira do que a verdade da História. A memória é um tipo de justiça. Em outras palavras, a memória lembra e a História esquece. Hoje em dia, a História deve proporcionar o conhecimento, mas a memória dá o significado. (NORA, 2009, p. 9)

\section{A Justiça de Transição no Brasil, o direito à memória e à verdade}

O que é a Justiça de Transição? Paulo Abrão Pires Junior, então Presidente da Comissão de Anistia ${ }^{4}$, explica que seu objetivo principal é promover a reconciliação nacional:

É um ramo de estudos muito complexo, que reúne profissionais de vários campos do conhecimento, como o Direito, Ciências Políticas, Sociologia, História, entre outras, com vistas a verificar quais processos de Justiça foram levados a cabo pelo conjunto dos poderes dos Estados nacionais, pela sociedade civil e por organismos internacionais para que, após o Estado de Exceção, a normalidade democrática pudesse se consolidar. (PIRES JUNIOR et al., 2009, p. 3)

A importância do debate sobre a justiça de transição no Brasil suscitou a criação de uma revista dedicada a essa problemática ${ }^{5}$, surgida em 2009, ou seja, 30 anos após a Lei da Anistia. Trata-se da Revista Anistia Política e Justiça de Transição, publicada pela Comissão da Anistia do Ministério da Justiça. Todos os números recebem contribuições de pesquisadores de outros países. O primeiro número recebeu contribuições de diversos países sobre o tema-título, "publicando pesquisas, relatórios e documentos sobre políticas de verdade e memória, de reparação, de justiça e de reformas das instituições" (GENRO; PIRES Jr., 2009). O número 10, último que foi publicado, é dedicado à cooperação das

\footnotetext{
${ }^{4}$ A Comissão da Anistia do Ministério da Justiça foi criada em 28/08/2001, pela Medida Provisória n. 2.151. Disponível em: <http://www.justica.gov.br/noticias/10a-revista-anistia-cooperacao-economicacom-a-ditadura-1>. Acesso em: 14 jan. 2016.
} 

1985)

empresas com o regime, demonstrando cabalmente a natureza empresarial do regime.

Enquanto dispositivo infocomunicacional e suporte de informação, "a revista é o meio privilegiado para a difusão do conhecimento" (COUZINET, 2009 , p. 24). Nesse sentido, a revista constitui também um elemento de mediação precioso, visando "uma forma cultural de pertencimento e de sociabilidade" (LAMIZET, 1999, p. 9), pois "as formas da mediação constituem o sistema de formas e de representações pelo qual nos tornamos atores sociais". Em seu número de estreia, os editores assinalam:

As ações previstas têm uma dimensão prospectiva, "cuja aplicação nas políticas públicas e na justiça podem trabalhar valores democráticos, no nível social, para a integração pedagógica da experiência que rompeu a ordem constitucional legítima na cultura nacional e para transformar o sofrimento do período em aprendizagem visando a não repetição". (PIRES Jr. et al., 2009, p. 3). ${ }^{6}$

A Comissão da Anistia trabalha sobre quatro temas-chave da justiça de transição: a reforma das instituições para a democracia; o direito à memória e à verdade; o direito à reparação e o direito ao tratamento igualitário e à justiça. Essas proposições integram o Plano Nacional de Direitos Humanos $(\mathrm{PNDH}-3)^{7}$ da Secretaria de Direitos Humanos da Presidência da República, cujo eixo maior se dedica ao Direito à memória e à verdade. Paralelamente a essas ações, o governo brasileiro colocou em prática a organização dos arquivos produzidos durante os 21 anos da Ditadura de 1964, em dois sentidos: primeiramente a partir da instituição do projeto Memórias Reveladas, que teve início em 2009, uma rede de instituições colaboradoras cuja responsabilidade e sede estão afetas ao Arquivo Nacional. A ideia é buscar documentos e arquivos onde quer que se encontrem, inclusive em países estrangeiros ${ }^{8}$, assim como reuni-los com o objetivo de torna-los acessíveis ao público. Anos depois, com imenso atraso se considerarmos que o regime terminou em 1985, foram promulgadas a Lei de Acesso à Informação e a Comissão Nacional da Verdade, após longo e acirrado debate, em $2012^{9}$. Uma sustentava a outra!

Além desses arquivos oficiais produzidos pela ação do Estado, uma outra fábrica produziu documentos, desde 2001, sob a direção da

\footnotetext{
${ }^{6}$ Além do seu papel de empreender uma política de reparação dos que sofreram perseguições políticas, a Comissão da Anistia desenvolve numerosos outros projetos. Ver: <http://portal.mj.gov.br/anistia/data/Pages/MJ20BF8FDBPTBRNN.htm>. Acesso em: 16 jan. 2016.

7 Aprovado pelo Decreto no 7.037, de 21 dez. 2009, atualizado pelo Decreto no 7.177, de 12 maio 2010. Disponível em: <www.sedh.gov.br>. Acesso em : 4 set. 2014.

${ }^{8}$ Há documentos sobre a resistência de exilados nos arquivos do Tribunal Russell II, em Roma. Essa Corte foi criada pelo senador socialista da época Lelio Basso que, em 1971, teve forte diálogo com exilados brasileiros [...]. Trata-se de documentos e testemunhos produzidos desde 1974 no curso das sessões que denunciavam as violações de direitos humanos no Brasil, Chile, Bolívia e Uruguai. Os arquivos foram enviados ao Ministério da Justiça pela Fundação Basso. Na França há arquivos da CIMADE depositados na BDIC (Biblioteca de Documentação Internacional Contemporânea) (SANTOS; ROLLAND, 2008, p. 198).

${ }^{9}$ Como se sabe, as duas leis foram promulgadas no mesmo dia, justamente para garantir ao mesmo tempo a abertura dos arquivos e o apoio legítimo da CNV.
} 
Comissão da Anistia, a partir não apenas dos registros de testemunhos de antigos perseguidos pelo regime militar, mas também documentos que pudessem provar os prejuízos causados pelo Estado de exceção. A construção do Memorial da Anistia, em Belo Horizonte, em curso em 2016, é um lugar de memória da ditadura previsto para abrigar cerca de 74.000 processos julgados pela Comissão de Anistia ainda em atividade ${ }^{10}$.

Paulo Abrão Pires Junior explica "que os processos podem ajudar a restabelecer a confiança entre os cidadãos e o Estado e devolver a dignidade às vítimas" (PIRES JUNIOR et al., 2009, p.7). O Tribunal Russell II é uma alusão à luta dos filósofos Bertrand Russell e Jean-Paul Sartre que fundaram o Tribunal Internacional dos Crimes de Guerra, em 1966, contra a Guerra do Vietnam, contra o chamado "crime do silêncio". Basso participou dos movimentos pela democracia e do I Congresso Brasileiro pela Anistia em 1978 (FILLIPI, 2012, p. 94).

A Fundação Basso doou à Comissão de Anistia quatro volumes compreendendo peças de processos (dossiês), testemunhos, e documentos os mais importantes produzidos durante os trabalhos do Tribunal Russell II. Além disso, haverá digitalização de documentos inéditos (cerca de 70.000 páginas) sobre os crimes dos regimes militares denunciados pelo Tribunal Russell $\mathrm{II}^{11}$.

Se os antigos resistentes à ditadura buscam inscrever suas experiências na memória coletiva nacional, isso não acontecerá sem o reconhecimento dos crimes cometidos e 0 pedido de perdão pelos criminosos ainda vivos e também pelos representantes das instituições que são as forças armadas. A reconciliação é um projeto que nos parece distante da realidade nessa fase pós-conflito, de justiça de transição, o que pode engendrar o retorno da violência. Aliás, sinais de perigo andam nos avisando...

A institucionalização dos lugares de memória da ditadura é uma estratégia política e pedagógica fundamental. Trata-se de transformar antigos espaços clandestinos de práticas de tortura e de sofrimento em centros de cultura, museus, memoriais, etc. Lembremos: A Comissão Nacional da Verdade identificou 230 lugares de tortura incluindo unidades militares e policiais e navios-prisões. Mas, se o combate pela atualização da memória deste período está ainda em curso, a apropriação desses lugares está longe de se concretizar. As forças políticas do passado estão ainda vivas, o que pode ser atestado pela existência de uma memória dividida, num país polarizado. A patrimonialização da experiência política só é possível quando se opera uma mudança de valores no seio da sociedade. A questão do patrimônio é essencialmente um problema de atribuição de valores (THIESEN; ALMEIDA, 2015). A existência de culturas políticas múltiplas pode explicar essa batalha pela memória. Falta informação? Faltam documentos e arquivos? Falta historiografia? Alguns

\footnotetext{
${ }^{10}$ Recentemente, os integrantes dessa Comissão foram substituídos de forma não democrática, no curso da interrupção abrupta do governo de Dilma Roussef, em 2016. Consta inclusive que um de seus atuais integrantes tem ligações com a Ditadura de 1964.

${ }^{11}$ Documento constante no final do periódico Revista Anistia Política e Justiça de Transição, n. 8, p. 438-459, 2009.
} 
marcos históricos sobre o Sistema de Informação e Contra-Informações (SISNI) que produziu documentos sensíveis, objeto da pesquisa que originou este artigo, são agora brevemente apresentados, numa tentativa de responder essas questões, bem como de caracterizar a natureza dos chamados documentos sensíveis.

\subsection{Os Arquivos do SISNI}

A produção documentária dos arquivos da ditadura militar brasileira iniciou-se antes do golpe de Estado de 1964. A análise da documentação abundante realizada pelos pesquisadores, particularmente os historiadores, mostrou que, alguns anos antes, houve vigilância sistemática estabelecida sobre supostos "comunistas", verdadeiro fantasma que assombrava as elites constituídas pelas forças armadas, a classe média, as mídias, as empresas, os banqueiros, setores expressivos da Igreja católica, como a Conferência Nacional dos Bispos do Brasil (CNBB), a Ordem dos Advogados do Brasil, etc.

Duas instituições foram criadas - O Instituto de Pesquisas e Estudos Sociais (IPES), em 1961, e o Instituto Brasileiro de Ação Democrática (IBAD) em 1959). O IPES foi mantido por capital privado, da mesma forma que o IBAD, sobretudo pelos EUA. "O IBAD agia de modo mais agressivo" em relação ao IPES (BRASIL. Comissão Nacional da Verdade, 2014, p. 319). O IBAD foi uma organização da CIA no Brasil que financiou diversas campanhas eleitorais de candidatos contrários ao Presidente João Goulart, em 1962. Uma vez denunciado esse esquema ilegal de transferência de recursos do governo americano, a partir de uma rede complexa de instituições nacionais e estrangeiras, uma Comissão de Investigação Parlamentar constatou o crime e o IBAD encerrou suas atividades por decisão do então Presidente da República. 20 milhões de dólares americanos foram investidos nesse período, segundo o Relatório da Comissão Nacional da Verdade (BRASIL. Comissão Nacional da Verdade, 2014, p. 319)

O IPES é o centro conspirador que formulou as reformas posteriormente implantadas pelo primeiro governo militar, do presidente Castelo Branco no dia seguinte do golpe de Estado. Daí ter sido considerado o "ovo da serpente" por René Armand Dreyfuss (1981).

Os primeiros documentos que integram os arquivos sensíveis do IPES foram "levados" do Serviço Federal de Informação e ContraInformações (SFICI), quando este foi extinto, após o golpe de Estado. Constitui também a célula inicial dos arquivos do Serviço Nacional de Informação, a mais importante instituição do SISNI, tendo ficado o SNI conhecido como "Ministério do silêncio", criado em 13 de junho de 1964, com o objetivo de supervisionar e coordenar as atividades de informação e contrainformação no Brasil e no exterior. Os documentos do antigo SFICI foram integrados aos arquivos do SNI pelas mãos de Golbery do Couto e Silva (FIGUEIREDO, 2005, p. 549). 

1985)

O general Golbery do Couto e Silva, antigo quadro do SFICI e do IPES, criou e dirigiu o SNI durante muitos anos. Este personagem-chave da Ditadura, formado pela Escola Superior de Guerra (ESG) após ter estudado na Escola do Forte Leavenworth, no Kansas (EUA), acumulou muito poder, não apenas porque todas as outras instituições do SISNI se dirigiam ao SNI, mas também porque uma "nuvem de segredos" protegia suas atividades. A lei isentava a divulgação ou a publicação de seus atos. Como revelou Vivien Ishaq, da Coordenação Regional do Arquivo Nacional, "sob total segredo começou a história do principal serviço de informação do regime militar no Brasil". "Cabeça" do SISNI, esta instituição, ao longo do tempo teve diversos escritórios de coleta de informações nas principais cidades do país. O SNI dispunha de pessoal contratado, mas seu dirigente podia requisitar funcionários de outros órgãos civis e militares em toda a administração do Estado. (ISHAQ, 2012, p. 69).

A colaboração intensiva de empresários antes e depois da instalação do regime já foi atestada pela historiografia, o que fez mudar a perspectiva de análise deste período durante 0 processo de redemocratização ${ }^{12}$. Esta "ruptura da legalidade" de fato constituiu um "golpe civil-militar", "empresarial-militar" e não um golpe simplesmente militar ${ }^{13}$.

As instituições que integravam o SISNI foram pensadas com o objetivo de controle, vigilância e punição de cidadãos supostamente "comunistas" ou resistentes ao regime, num tripé estruturado para atingir todo o país ${ }^{14}$. O Sistema estruturado sobre um conjunto complexo de instituições é, de fato, uma fábrica de documentos que tem engrenagens bastante complexas. Para se desenvolver, expandiu-se por todo o território nacional e no exterior, contendo instituições militares e civis. Apesar da impossibilidade de analisar todas as instituições, é preciso evocar a maneira pela qual a comunidade de informação produzia documentos e fazia circular num sistema de informação de valor jurídico e de inteligência, integrado por 16 órgãos especializados cujas malhas tinham seu fio centralizado no SNI. Estima-se em 17 milhões de documentos recolhidos aos arquivos ( $20 \%$ da produção total), cuja circulação se estabelecia entre essas instituições com acesso restrito aos altos escalões da hierarquia militar.

As Diretorias de Segurança e Informações (DSIs) e as Assessorias de Segurança e Informações (ASIs) existiam em todos os ministérios civis responsáveis por acompanhar os órgãos da administração indireta, autarquias e universidades; as Assessorias Especiais de Segurança e

\footnotetext{
${ }^{12}$ A tese de Campos (2012) ilustra a participação ativa do setor de infraestrutura no golpe de Estado e conta como as empresas de construção civil permaneceram próximas ao Estado mesmo após a redemocratização.

13 Além das teses, livros, documentários, a Revista Anistia Política e Justiça de Transição, do Ministério da Justiça, dedicou o n. 10 a essa temática. Disponível em: <http://www.justica.gov.br/noticias/10arevista-anistia-cooperacao-economica-com-a-ditadura- 1/revista_anistia.pdf $>$. Acesso em: 14 jan. 2016. Ver também: BRASIL. Comissão Nacional da Verdade. Relatório final. Brasília, 2014. v. II, p. 303-328. Disponível em: <http://www.cnv.gov.br/>. Acesso em: 14 jan. 2016.

${ }^{14}$ A propaganda massiva e sistemática nas médias, sobretudo no rádio, desempenhava o papel de formar o pensamento social em favor do regime, enquanto a censura filtrava os conteúdos das informações, inclusive do cinema, letras de músicas, teatro, etc.
} 
Informações (AESIs) complementavam o setor civil do SISNI nas empresas do Estado e em algumas universidades; as Segundas seções do Estado-Maior das Forças Armadas chamadas F2; do Exército (S2); da Marinha (M2), da Aeronáutica (A2); dos 3 ministérios militares, CIE; CISA; CENIMAR; os serviços secretos da Polícia Federal; os DOPS (Departamentos de Ordem Pública e Social) e os serviços secretos das Polícias militares, P2; os Centros de Operações de Defesa InternaDestacamentos de Operações de Informação (CODI-DOI), o "braço operacional" da repressão; Centro de Informação do Exterior, do Ministério das Relações Exteriores (CIEX) encarregado de vigiar os exilados e de enviar informações ao SNI, CIE, CISA e CENIMAR, sobre o qual não existe legislação de criação; CGI (Comissão Geral de Investigação, do Ministério da Justiça); Conselho de Segurança Nacional (CSN) (FAJARDO, 1993; ISHAQ, 2012; THIESEN, 2011).

Qual o modus operandi do regime? Sob os eixos da Doutrina de Segurança Nacional, importada dos EUA e ensinada na Escola Superior de Guerra, praticavam a espionagem, a contra-informação, escutas, criptografia, registros telefônicos, infiltrações nas organizações de resistência e nas universidades, violação de correspondências, delações, etc. etc.

A Escola Nacional de Informação foi criada em 1971, subordinada ao SNI. Cerca de 120 pessoas, sendo 60 civis, foram formadas anualmente pela Escola Nacional de Informação (EsNI) (FICO, 2001, p. 82). Os documentos revelam tanto a existência de delatores remunerados (nesse caso, anônimos) quanto de delatores sob tortura nos interrogatórios, cujos nomes são revelados, além de voluntários (colegas, vizinhos, porteiros, etc.) cujos nomes também eram declarados. A proteção é sempre para os seus! A natureza desses documentos é absolutamente singular.

Havia ainda uma "política da caserna" que engendrava conflitos sólidos no seio da comunidade de informação. Pertencer a essa elite militar poderia produzir ganhos em matéria de gestão de posições, de promoções, de poderes. A informação é assim uma arma simbólica que dá status profissional e social (CHIRIO, 2012, p. 176). Portanto, era necessário "mostrar seus bons serviços" atestados pelos documentos.

O atributo "sensível" ligado aos arquivos, documentos e assuntos origina-se de episódios conflitivos do século XX estudados por historiadores, juristas, arquivistas e, mais recentemente, por pesquisadores em Ciência da Informação para quem o documento é material e objeto de pesquisa. São qualificados de "sensíveis" porque esses acontecimentos produziram pistas que podem desvelar fatos, nomes, experiências e circunstâncias comprometedoras das personalidades da vida pública e privada. (THIESEN, 2014, p. 83) "Produzidos pelos serviços de polícia, de informação e de vigilância, para os quais a distinção entre vida pública e profissional não existia" (COMBE, 2011 , p. 23) portavam o carimbo de "secretos" e se inscreviam na categoria de "sensíveis". 
A máquina que produziu suplícios, torturas, sofrimentos, desaparecimentos e mortes é a mesma que produziu esses documentos. Por trás das ações comandadas pelos governos militares sob a mão pesada do SNI, havia ferramentas de recuperação de informações poderosas, capazes de encontrar dados rapidamente ${ }^{15}$. Como isso era possível nos anos sessenta? Essa resposta já estou buscando em minha nova pesquisa.

No decorrer do tempo, conflitos e disputas internas se agravaram e a perda do controle dessa máquina fez com que o Gen. Golbery dissesse: "criei um monstro". O SNI só foi extinto em 1990. Hoje esses arquivos disponíveis aos usuários são utilizados contra seus produtores para provar sua culpabilidade. É o chamado "efeito boomerang"!

Contudo, os arquivos mais importantes produzidos pela "comunidade de informação" das três armas (CIE, CISA e CENIMAR) jamais foram recolhidos ao Arquivo Nacional. Antigos oficiais responsáveis por sua guarda e conservação declararam que os arquivos foram destruídos no final do regime. No entanto, existem indícios fortes de que tais arquivos jamais foram destruídos ${ }^{16}$. Essas instituições de inteligência agiam em rede no SISNI e constituíam o terror dos prisioneiros políticos, que sobre essa experiência inesquecível deram e dão seus testemunhos! Aqui entramos em outro aspecto do processo de reconstrução da memória social - os testemunhos.

\subsection{0 testemunho ou as memórias declaradas}

No prelúdio da segunda parte de seu livro dedicado às questões da memória, da história e do esquecimento, Paul Ricoeur lança mão do mito de origem da escrita, no Fedro de Platão, mas também inspirado na Farmácia de Platão da pluma de Jacques Derrida, lançando a pergunta: "da escrita da história, também, não se deveria perguntar se ela é remédio ou veneno?" (RICOEUR, 2007, p. 151). No curso das suas argumentações, tendo por base a ambiguidade característica de todo mito, o autor analisa, entre outros temas ligados ao que denominou de Fase Documental: a memória Arquivada, o testemunho, o arquivo, a prova documental. Sua preocupação epistemológica é com a justa memória, o testemunho e os arquivos, a história e o esquecimento (THIESEN, 2015b).

Recorto da obra suas reflexões sobre o que denominou de "crise do testemunho", sobretudo quando se refere ao caso limite dos testemunhos escritos na dor. Referindo-se, contudo, à experiência testemunhal de Primo Levi, sobretudo em sua derradeira obra "Os afogados e os sobreviventes", o historiador se pergunta se "esse tipo de testemunho

\footnotetext{
5 Havia um banco de dados do Sistema de Arquivamento e Recuperação de Documentos (SARDI) que englobava outros 19 bancos de dados (ISHAQ, 2012, p. 75). Esse Manual foi analisado em outro artigo. Ver THIESEN (2018).

${ }^{16}$ Há relatos sobre o recolhimento dos arquivos do CENIMAR (ou parte deles) ao Memorial da Anistia, na UFMG. Sobre o assunto ver FIGUEIREDO (2015) e RODRIGUES (2017).
} 
parece constituir uma exceção dentro do processo historiográfico?" Ele explica:

Trata-se de experiências extremas, propriamente extraordinárias que abrem para si um difícil caminho ao encontro de capacidades limitadas, ordinárias de recepção, de ouvintes educados para uma compreensão compartilhada. Essa compreensão foi erigida sobre as bases de um senso da semelhança humana no plano das situações, dos sentimentos, dos pensamentos, das ações. Ora, a experiência a ser transmitida é a de uma inumanidade sem comparação com a experiência do homem ordinário. (RICOEUR, 2007, p. 186).

Primo Levi é um sobrevivente do campo de concentração de Auschwitz e, como se sabe, passou grande parte de sua vida no pósguerra exercendo a escrita do testemunho. Na sua última obra denuncia a destruição de todos os arquivos dos Lager "nos últimos dias da guerra" (LEVI, 2004, p. 10), o que explicaria, em parte, sua dedicação à narrativa do trauma e da dor. Ao criar a noção de "zona cinzenta" colocou-se de forma crítica no contexto de sua experiência concentracionária. Referia-se aos prisioneiros que viveram nos campos de concentração no desempenho de funções que tornavam ambíguas as posições que ocupavam no cotidiano dos campos, escapando da "solução final". Todorov, recémfalecido, explica que o termo zona cinzenta...

[...] designa, primeiro, todos os que não podem ser classificados simplesmente como 'prisioneiros' ou 'guardas'. De fato, tanto no Lager como no Gulag, os guardas superiores, SS ou NKVD17, asseguram-se da ajuda de muitos presos que eles elevam acima da massa, mantendo-os ao mesmo tempo bem abaixo deles mesmos: Kapos habitualmente recrutados entre os criminosos comuns, pessoal técnico ou médico, operários especializados ou encarregados das tarefas específicas (TODOROV, 2002, p. 213).

Para a compreensão dessa exceção que constituem as situações extremas, analisadas por Paul Ricoeur, seria necessário conhecer a regra, contida em sua pergunta: "até que ponto o testemunho é confiável?" Essa pergunta, diz ele, coloca na balança a confiança e a suspeita. Remédio ou veneno? Sem estender a discussão contida em sua profunda análise, considerando os limites de tempo, ficamos com a questão central, certamente de natureza ética, pois "trata-se agora de lutar contra a incredulidade e a vontade de esquecer". (RICOEUR, 2007, p. 187). O que resta de Auschwitz não seria o testemunho e o arquivo de memórias declaradas? O próprio Primo Levi reflete sobre a existência de "lembranças influenciadas por notícias havidas mais tarde, por leituras ou por narrações alheias" (LEVI, 2004, p. 16), apontando para o conhecido fenômeno da ressignificação da memória. Nem por isso deixou de testemunhar, buscando a superação de suas próprias inquietações. Nem por isso o fenômeno da memória social perde valor. Em todos os campos

\footnotetext{
${ }_{17}$ People's Comissariat for Internal Affairs, ou NKVD é a denominação da polícia secreta criada durante o stalinismo, tendo mudado de nome por diversas ocasiões. Hoje é conhecida por KGB. Disponível em: <http://www.loc.gov/exhibits/archives/secr.html>. Acesso em: 8 agosto 2015.
} 
do conhecimento há atualizações em função dos avanços das pesquisas e das mudanças sociais.

Graças a testemunhos de sobreviventes de regimes de exceção tornou-se possível reconstituir diversos acontecimentos trágicos, como o Holocausto, Hiroshima e Nagasaki, a Guerra do Vietnã, os Gulags soviéticos, as ditaduras do Cone Sul, entre muitas outras. Daí o alerta de Axel Plathe, no sentido de que

[...] é preciso converter [os arquivos da repressão ou arquivos sensíveis] em uma ferramenta que permitirá a criação de novas estruturas legais e éticas e que assumirá o estabelecimento de novas relações sociais e políticas. A maneira pela qual jovens democracias gerenciam e utilizam esses arquivos mostra, de forma bastante evidente, sua capacidade de serem verdadeiras democracias. (PLATHE, 1998, p. 128).

Vimos no desenrolar dessa argumentação que as contradições, conflitos e impasses na seleção e uso das fontes são de natureza política, certamente, mas prevalece como pano de fundo a ética da pesquisa que desafia o pesquisador a buscar aproximações com a verdade na análise do documento produzido em regimes de exceção, do testemunho oral gravado que se transforma em "memória arquivada, documentada" (RICOEUR, 2007, p. 189) e da prova documental que passaria, conforme este autor, por

uma epistemologia vigilante [que] nos adverte aqui contra a ilusão de crer que aquilo a que chamamos fato coincide com aquilo que realmente se passou, ou até mesmo com a memória vivida que dele têm as testemunhas oculares, como se os fatos dormissem nos documentos até que os historiadores dali os extraísse". (RICOEUR, 2007, p. 189)

Beatriz Sarlo, professora e crítica de literatura da Universidade de Buenos Aires, afirma que

o testemunho é uma instituição da sociedade, que tem a ver com a esfera jurídica e com um laço social de confiança, como apontou Arendt. [...] quando o testemunho narra a morte ou a vexação extrema, esse laço estabelece também uma cena para o luto, fundando assim uma comunidade ali onde ela foi destruída. (SARLO, 2007, p. 50)

A importância do testemunho, em nossa história recente, realizado em primeira pessoa, pode ser atestada por inúmeros ex-militantes que resistiram à Ditadura de 1964 no Brasil. Inês Etienne Romeu, da organização VAR-PALMARES, a quem presto uma homenagem neste dia internacionalmente dedicado às mulheres, foi a única sobrevivente da Casa da Morte em Petrópolis, um centro clandestino de tortura e extermínio que, até onde se sabe, teria sido o único a funcionar fora das instalações militares. Priscila Almeida conta que a denúncia sobre a existência do espaço foi feita em 1979, 
[...] com a entrega do testemunho de Inês Etienne Romeu à Ordem dos Advogados (OAB-RJ). [...] Redigido em 1971, enquanto ainda estava em recuperação na Casa de Saúde Santa Maria, o testemunho denunciava os maus tratos sofridos, as características físicas e comportamentais de seus algozes e a vinculação do espaço com a alta hierarquia do Centro de Informações do Exército (CIE) ${ }^{18}$.

A repercussão do testemunho foi veiculada por diversos órgãos de imprensa em fevereiro de 1981, quando a vítima e uma caravana organizada pela OAB-RJ foram ao local e tiveram um encontro com o proprietário da casa, Mario Lodders, que durante toda a sabatina feita pelos advogados negou ter conhecimento do que se passava na Casa e que apenas a havia emprestado a um amigo. Naquele mesmo ano, Inês Etienne Romeu denunciou publicamente o médicoassistente de torturas, Amílcar Lobo, atuante na Casa da Morte. Em 1986, o médico lançou seu livro de memórias e concedeu entrevistas a jornais impressos, afirmando sua atuação na Casa e a ligação direta do espaço aos oficiais do CIE (ALMEIDA, 2015, p. 202).

O relato de Inês é bastante minucioso, tendo permitido a identificação e comprovação da existência desse imóvel, bem como dos demais crimes ali cometidos, apesar do intenso sofrimento diário a que foi submetida. É bastante conhecida a estratégia de denúncia e desqualificação de testemunhos dessa natureza, no sentido de despistar as investigações levadas a efeito pelas instituições que sucederam o antigo regime. Contudo, nos momentos que precederam a instalação da Comissão Nacional da Verdade, em 2012, criada desde o ano anterior, personagens ligados aos atos extremos começaram a sair das sombras. Se de fato era necessária a confirmação do ocorrido e relatado no depoimento de Inês, sobraram confirmações:

Em acontecimentos mais recentes, podemos destacar o vídeodepoimento prestado por Ubirajara Ribeiro de Souza ao procurador da Justiça Militar Otávio Bravo (2011), o livro de memórias do exagente da polícia civil Cláudio Guerra (2012) e os depoimentos oficiais de Marival Chaves (2013) e do ex-tenente-coronel Paulo Malhães (2014) prestados à Comissão Nacional da Verdade, que confirmam a existência do centro de extermínio, ou "casa de conveniência", alcunha utilizada pelos militares. (ALMEIDA, 2015, p. 202)

Da condição de espaço clandestino utilizado para a perpetração de crimes cometidos por agentes a serviço do Estado, categorizada como centro de tortura, mortes e desaparecimentos, a Casa da Morte reivindica sua atualização como lugar de memória que revela segredos e crueldades, buscando uma outra pedagogia:

A força que ganha o testemunho de sua única sobrevivente faz com que a Casa da Morte de Petrópolis seja o foco de uma campanha

\footnotetext{
${ }^{18} \mathrm{O}$ depoimento de Inês Etienne Romeu, assim como diversos vídeos sobre os acontecimentos da Casa da Morte estão disponíveis em: <http://www.epsjv.fiocruz.br/upload/doc/DEPOIMENTO_INES.pdf>. Acesso em: 8 agosto 2015.
} 
iniciada em 2010 pelo Conselho de Defesa dos Direitos Humanos de Petrópolis, com o apoio de grupos de movimentos civis, para a desapropriação do imóvel e sua posterior ocupação por um memorial pela Liberdade, Verdade e Justiça. A desapropriação do imóvel, em 2012, pela Prefeitura de Petrópolis foi uma primeira conquista em direção à legitimação e ressignificação do espaço. No âmbito estatal, a incorporação da Casa da Morte como caso especial de investigação sobre o paradeiro de desaparecidos políticos e identificação das estruturas utilizadas pela repressão para prisão, tortura e extermínio dão um peso inconteste em relação à preservação histórica do local como medida de reparação simbólica. (ALMEIDA, 2015, p. 200).

Inês Etienne Romeu faleceu em 27 de abril de 2015, em sua residência. Dormia! Nascida em Pouso Alegre, em 1942, identifica-se no seu depoimento como bancária. Durante toda a sua vida lutou para ver sua experiência-limite transformada em memória declarada, inscrita nos arquivos e reconhecida. Narrativa em primeira pessoa, típica do testemunho!

Questões epistemológicas desafiam os pesquisadores que lutam para compreender como analisar documentos sensíveis sem cair nas armadilhas da escrita policial. Para esse propósito, é necessário definir tanto ferramentas quantitativas de exploração de dados, quanto metodologias de natureza qualitativa, notadamente a análise e confronto de testemunhas, na via de uma ética da memória que nos coloque na fronteira entre a informação, a memória e a história. É fácil verificar que a memória desse período, após mais de 50 anos, ainda é difusa, dividida, cinzenta e seu reenquadramento suscita novas pesquisas e análises.

A justa memória, a verdade e a ética são ainda um projeto inacabado devido aos conflitos políticos e sociais, acomodações e conciliações de interesses das forças políticas em meio a esta cultura política e jurídica. E assim, uma parte da memória social, da verdade (alethea) permanece ainda perdida no rio do esquecimento (lethe). As sementes da memória aguardam o tempo propício para aflorar do silêncio.

\section{Referências}

ALMEIDA, P. C. Direitos humanos e espaços concretos: paralelos e reflexões acerca da experiência memorial em antigos centros clandestinos no Brasil e no Chile. In: CARRARA, O. V. (Org.). Direitos humanos na América Latina. Nova Petrópolis: Nova Harmonia / São Leopoldo: Kariwa, 2015. p.191-210.

ANHEIM, É.; PONCET, O. Fabrique des archives, fabrique de I'histoire. Revue de synthèse, n. 5, p.1-14, 2004.

BERSTEIN, S. Culturas políticas e historiografia. In: AZEVEDO, C et al. (Orgs.). Cultura política, memória e historiografia. Rio de Janeiro: Ed. FGV, 2009. p. 29-46. 
BRASIL. Comissão Nacional da Verdade. Relatório. Brasília, 2014. Disponível em: <www.cnv.gov.br>. Acesso: 15 abr. 2015.

CAMPOS, P. H. A ditadura dos empreiteiros: as empresas nacionais de construção pesada, suas formas associativas e o Estado ditatorial brasileiro, 1964-1985. 584f. 2012. Tese (Doutorado em História Social) Universidade Federal Fluminense, Niterói, 2012.

CHIRIO, M. A política nos quartéis: revoltas e protestos de oficiais na ditadura militar brasileira. Rio de Janeiro: Zahar, 2012.

COMBE, S. Resistir à razão de Estado. In: SALOMON, M. (Org.) Saber dos arquivos. Goiânia: Edições Ricochete, 2011.

COUZINET, V. Dispositifs info-communicationnels : contributions à une définition. In : COUZINET, V. (Dir.). Dispositifs info-communicationnels : questions de médiations documentaires. Paris : Hermes; Lavoisier, 2009. p. 19-30.

DREIFUSS, R. A. 1964 : a conquista do Estado - ação política, poder e golpe de classe. Petrópolis: Vozes, 1981.

FAJARDO, S. P. Espionagem política: instituições e processo no Rio Grande do Sul. 1993. 56f. Dissertação (Mestrado em Sociologia) - Programa de Pós-Graduação em Sociologia, Universidade Federal do Rio Grande do Sul, 1993.

FARGE, A. Le goût de l'archive. Paris: Éditions du Seuil, 1989.

FICO, C. Como eles agiam. Rio de Janeiro; São Paulo: Record, 2001.

FIGUEIREDO, L. O ministério do silêncio. Rio de Janeiro: Record, 2005.

FIGUEIREDO, L. Lugar nenhum: militares e civis na ocultação dos documentos da ditadura. São Paulo: Companhia das Letras, 2015.

FILLIPI, A. O legado de Lelio Basso na América latina. In: SEMINÁRIO INTERNACIONAL DE DIREITOS HUMANOS DA UNIVERSIDADE FEDERAL DA PARAÍBA (UFPB), 7., João Pessoa, 2012. Anais... João Pessoa, 2012. Disponível em: http://docplayer.com.br/16935710-O-legado-de-leliobasso-na-america-do-sul-e-seus-arquivos-de-roma.html]. Acesso em: 19 fev. 2107.

SANTOS, I.-M. F. dos; ROLLAND, D. (Dir.). Le Brésil des gouvernements militaires et l'exil 1964-1985. Paris: L'Harmattan, 2008.

FRANÇOIS, É. Os "tesouros" da Stasi ou a miragem dos arquivos. In: BOUTIER, J.; JULIA, D. (Orgs.). Passados recompostos: campos e canteiros da História. Rio de Janeiro: Editora UFRJ; Editora FGV, 1998. p. 155-161.

GENRO, T.; PIRES Jr., P. A. Apresentação. Revista Anistia Política e Justiça de Transição, Brasília, v. 1, n. 1, p. 5-9, 2009.

ISHAQ, V. Introdução. In: ISHAQ, V. (Org.). A escrita da repressão e da subversão: 1964-1985. Rio de Janeiro: Arquivo Nacional, 2012. p. 11-35 
LAMIZET, B. La médiation culturelle. Paris: I'Harmattan, 1999.

LECLERC, N. P.-G. La réconciliation en Afrique du Sud: la Commission Vérité et Réconciliation. In : HOAREAU-DODINAU, J. ; ROUSSEAUX, X. ; TEXIER, P. (Dir.) Le pardon. Limoges: Presses Universitaires de Limoges, 1999. (Cahiers de I'Institut d'Anthropologie Juridique, 3) .

LEVI, P. Os afogados e os sobreviventes: os delitos, os castigos, as penas, as impunidades. Trad. Luiz Sergio Henriques. São Paulo: Paz e Terra, 2004.

NORA, P. Memória: da liberdade à tirania. Revista MUSAS, n. 4, p. 6-10, 2009.

PIRES Jr., P. A. et al. Prefácio. Revista Anistia Política e Justiça de Transição, Brasília, v. 1, n. 1, p. 12-21, 2009.

PLATHE, A. L'UNESCO et la gestion des archives des services de sécurité des anciens régimes repressifs. In : MEMOIRE et histoire : Les états européens face aux droits des citoyens du XXI siècle. Bucarest, 1998. p. 127-134.

RICOEUR, P. A memória, a história, o esquecimento. Campinas (SP): Editora da Unicamp, 2007.

RODRIGUES, V. A. C. Documentos invisíveis: arquivos da ditadura militar e acesso à informação em tempos de justiça de transição no Brasil. Aracaju: EDISE, 2017.

SARLO, B. Tempo passado, cultura da memória e guinada subjetiva. São Paulo: Companhia das Letras; Belo Horizonte: UFMG, 2007.

THIESEN, I. Inteligência informacional: dialogando com a informação, a memória e a história. In: THIESEN, I. (Org.). Imagens da clausura na Ditadura de 1964. Rio de Janeiro: 7Letras, 2011. p. 216-236.

THIESEN, I. Documentos sensíveis: da produção à validação. In: COLÓQUIO INTERNACIONAL DA REDE MUSSI, 3., 2014, Salvador. Anais... Salvador: UFBA, 2014. p. 78-96

THIESEN, I.; ALMEIDA, P. C. Lugares de memória da Ditadura e a patrimonialização da experiência política. Revista Museologia \& Interdisciplinaridade, Brasília, v. 4, n. 8, p.15-30, 2015.

THIESEN, I. Ética da memória: documento, testemunho e verdade no contexto da justiça de transição no Brasil. In: FONSECA, V. M. M. da; LIMA, M. H. T. de F.; FREITAS, L. S. de. Ética e políticas de informação: agentes, regimes, mediações. Niterói: UFF, 2005b. [No prelo].

THIESEN, I. Document par intention: réflexions sur les « documents sensible ». In : COLLOQUE INTERNATIONAL D'ISKO-FRANCE, 11., 2017, Paris, UNESCO. Actes... London: ISTE Éditions, 2018. p. 239-250.

TODOROV, T. Memória do mal, tentação do bem: indagações sobre o século XX. São Paulo: Arx, 2002. 
UNESCO. Les archives sont au coeur de la société de l'information, 2016. Disponible en ligne: <http://portal.unesco.org/ci/fr/ev.php-

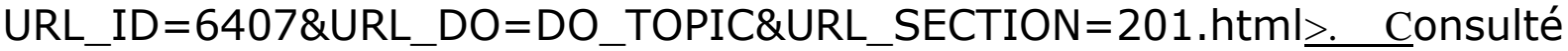
le: 14 jan. 2016. 